\title{
Fire AND CARbon CYCling In THE SubAPLINE Forests OF Yellowstone National PARK
}

\author{
$\longrightarrow>$ \\ DANIEL M. KASHIAN $\uparrow$ DEPARTMENT OF BIOLOGICAL SCIENCES \\ WAYNE STATE UNIVERSITY $\downarrow$ DETROIT \\ DANIEL B. TINKER \ DEPARTMENT OF BOTANY $\downarrow$ UNIVERSITY OF WYOMING \\ LARAMIE \\ MONICA G. TURNER $\downarrow$ DEPARTMENT OF ZOOLOGY $\downarrow$ UNIVERSITY OF WISCONSIN \\ MADISON \\ WiLliam H. ROMME WARNER COLLEGE OF NATURAL RESOURCES \\ COLORADO STATE UNIVERSITY $\$ FORT COLLINS \\ MiCHAEL G. RYAN $\downarrow$ ROCKY MOUNTAIN RESEARCH STATION \\ COLORADO STATE UNIVERSITY $\downarrow$ FORT COLLINS
}

\section{$\downarrow$ INTRODUCTION}

Our research group carried out two projects through UW-NPS and the AMK Ranch in 2007, a field study (project \#1) and a workshop for managers (project \#2).

In 2004 we had initiated a field study of carbon stocks along a replicated chronosequence of stands in Yellowstone National Park that had burned at varying times from ca. $1700 \mathrm{AD}$ through 1988. In each stand we measured all of the major carbon pools (including live biomass, dead biomass, and soil carbon) to characterize changes over time in net ecosystem production (the net balance between carbon uptake and loss from an ecosystem). These empirical data were then used to evaluate the potential effects of changing climate and changing fire frequency on how the Yellowstone landscape as a whole functions as either a carbon sink or a carbon source in the global carbon cycle.
After analyzing the data from our initial field season, we discovered an apparent anomaly in our results: total carbon stocks in the recently burned stands (1988) were substantially lower than predicted. This could have resulted from a sampling error, or could indicate that the stands in our sample selection were not representative of recently burned stands throughout the landscape. Therefore, we returned to the field in 2007 to conduct additional sampling to distinguish between these two explanations. Details are provided below under project \#1, field studies.

In addition to the field study, we hosted a workshop on fire and carbon storage at the AMK Ranch for land managers. The purpose of the workshop was to provide a synthesis and summary of our field and modeling studies of the previous three years, as well as an update on current issues and thinking about the roles of forests and fires in global carbon dynamics. This workshop is described below under project \#2, workshop for managers. 
Project \#1: Field Study - Testing Results from Previous Year's Sampling

A three-week field season at the AMK was used in 2007 to field check some of the data collected in 2004-07 in Yellowstone National Park as part of a study examining effects of fire on carbon cycling (funded by the Joint Fire Sciences Program). This work included a 8person field crew, consisted of three undergraduates and one technician from Wayne State University, two recent graduates from Colorado State University, and Brandon and Janice Corcoran, all supervised by Dan Kashian and Mike Ryan during the first week of field work.

Our initial objective was to re-sample and re-quantify dead coarse wood originally sampled in our chronosequence that measured changes in carbon storage with increasing stand age. The original data suggested that far less carbon is stored in recently burned stands $(<25$ years old) than in older stands. This is problematical, as similar amounts of carbon should be present in all stand ages because most killed biomass (and thus carbon) remains after the fire. Our youngest age class had similar amounts of dead biomass as our oldest age class, when we expected to find approximately $50 \%$ more based on the likely amount of biomass killed by the fire (Figure 1).

Live biomass in young stands was significantly less than that in older stands, consistent with our data, and we therefore hypothesized that our sampling underrepresented the amount of dead biomass in the younger stands.
During the first week of the field season we re-sampled all 15 of the stands in our youngest age class using alternative methods of line intercept sampling that both increased the length of the transects and altered their orientation to avoid any bias in the predominant direction of the downfall. Surprisingly, our resampling revealed estimates of dead biomass within $<5 \%$ of our original estimates. We therefore hypothesized that the 15 sampled young stands, or some significant subset of them, were not representative of typical values of dead biomass found in recently burned stands in Yellowstone.

We employed a set of random samples of biomass across the subalpine plateaus of Yellowstone National Park as an attempt to quantify the "average" basal area of burned and unburned stands for comparison to our own chronosequence stands. We were also interested in quantifying the amount of dead biomass prior to the last fire (using separate measurements of charred vs. un-charred coarse wood) to ensure that pre-disturbance dead biomass was not biasing the estimates. We randomly sampled basal area of dead biomass in 40 burned stands using line transects and 40 unburned stands using prism sampling. Burned stands were sampled 200 meters from the roads and were spaced at least 2.5 miles apart; unburned stands were also sampled 200 meters from the roads and were at least 1.5 miles apart. Unburned stands were sampled for standing trees only, and thus estimates of dead biomass in unburned stands are inherently low because they do not include fallen dead wood.

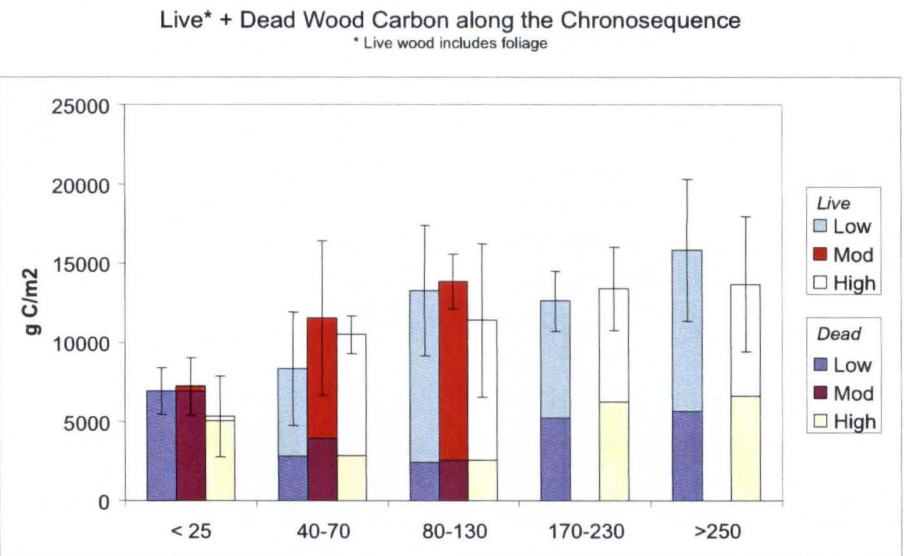

Figure 1: Mean carbon in live and dead pools across a chronosequence of 77 lodgepole pine stands sampled in Yellowstone National Park (preliminary results - please do not distribute). 
We found that the 15 stands sampled as part of our chronosequence have likely underestimated typical values of dead biomass. Total biomass of our young stands is lower (though variable) than that of the randomly sapmpled unburned stands (Figure 2). Total biomass of random burned and unburned stands was approximately equal, as we expected, and biomass in the random unburned stands approximates that of the older stands in the chronosequence.

\section{Project \#2: Workshop for Managers - Fire and} Carbon Storage in Forests

We held a one-day workshop entitled (Fire and Carbon Storage in Forests" on May 30, 2007, from 9am-5pm, in the Berol Lodge at the AMK Ranch. The purpose of the workshop was to inform land managers and to have discussion and feedback about the background and new developments in:
- Forests in the regional carbon cycle

- Forest potential for carbon sequestration

- Fire and carbon cycling - short and long-term effects

- Remote sensing of forest disturbance

- Presenters included: Mike Ryan, USDA Forest Service; Bill Romme, Colorado State University; Mark Harmon, Oregon State University; and Jeff Hicke, University of Idaho.

- Attending the workshop were managers from Grand Teton National Park and surrounding national forests.

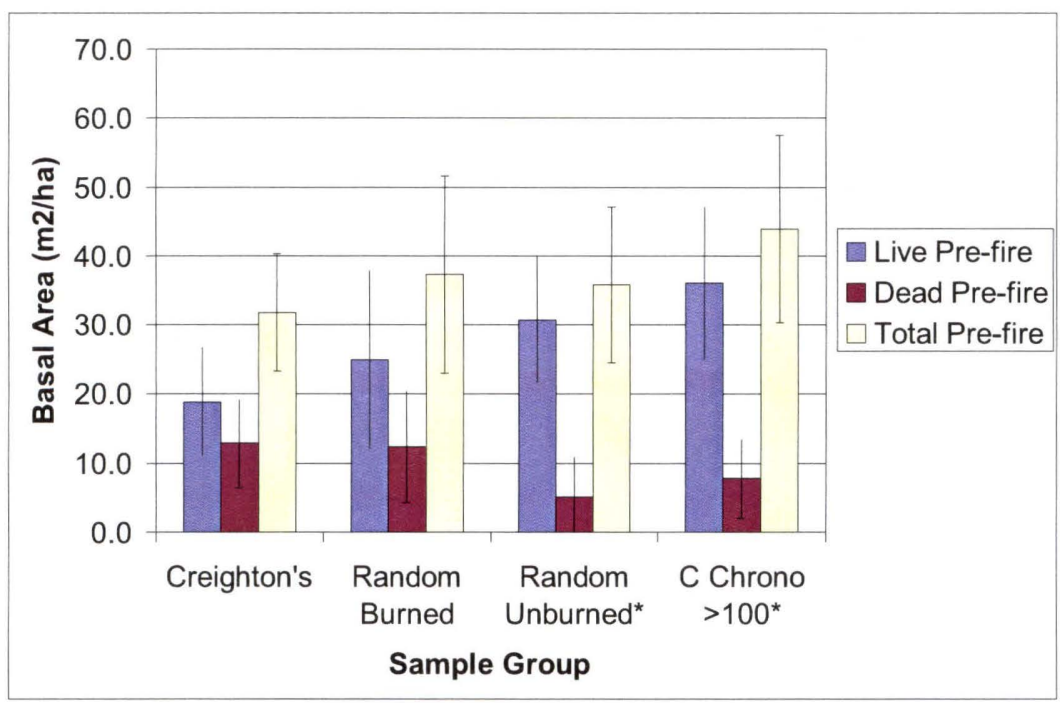

Figure 2: Mean live and dead basal area for lodgepole pine stands sampled randomly and within a chronosequence in Yellowstone National Park (preliminary results - please do not distribute). 